\title{
Stationary and mobile particulate matter concentration measurement in Miskolc
}

\author{
Cs. BÁthory ${ }^{1}$, P. PeCSMÁNY2 ${ }^{2}$ L. SZALONTAI ${ }^{3}$, Á. B. PALOTÁs ${ }^{4}$ \\ 1University of Miskolc, Institute of Energy and Quality Affairs, tuzcsongor@uni-miskolc.hu \\ 2University of Miskolc, Institute of Geography and Geoinformatics, ecopeter@uni-miskolc.hu \\ ${ }^{3}$ University of Miskolc, Institute of Geography and Geoinformatics, ÉMI Non-Profit LLC, ecoszalo@uni-miskolc.hu \\ 4University of Miskolc, Institute of Energy and Quality Affairs, arpad.palotas@uni-miskolc.hu
}

Abstract. A stationary and mobile device based on a low-cost dust sensor (Plantower PMS7003) was used to study particulate matter (PM) concentration in Miskolc. The stationary device was placed at the automatic monitoring station of the National Air Quality Measurement Network (OLM) in Martintelep, Miskolc. The mobile device was used to walk 4 streets along a square route with a total length of $800 \mathrm{~m}$. Measurements were made on two days (September 9 and 11) between 7am and 9am, which according to preliminary experience coincided with the morning rush hour. The access route includes the OLM monitoring station, a busy road, two bypasses, a parking lot, and a smaller roadway blocked by traffic. The measured PM1, PM2.5, PM10 concentrations of the mobile device were interpolated on a circuit-by-circuit basis in ArcGIS, and conclusions were drawn for the area. The concentration of stationary and mobile devices was compared.

\section{Introduction}

Because of its effects on human health [1] and climate [2], there are worldwide standards for particulate matter (PM) environmental concentrations $[3,4]$. Compliance with the limit values is monitored based on high-quality and expensive devices. The European Union's Air Quality Directive 2008/50/EC (AQD) [5] allow to use indicative, additional measurements that meet a less strict data quality objective than accredited monitoring networks. Low-cost dust sensors may be suitable for such indicative measurements. Over the last decade, sensor-based air pollution monitoring systems have become more prominent, thanks for their low cost, small dimensions, high spatial resolution and they can provide detailed data on air pollution in cities. Due to their small size, the sensors are easy to install on fix point or mobilize, and thus become accessible to the public for air quality monitoring [6]. Most of the studies focusing on stationary networks [7, 8] or mobile sensing [9-11] but just a few with the combination of them $[12,13]$ measured with low-cost PM sensors. In this context, we are currently experiencing a paradigm shift in how and who observes air quality $[14,15]$. This paper aims to show and analyse the measured PM1, PM2.5, PM10 concentrations of a stationary and a mobile device in a residential area. 


\section{Material and methods}

The mobile and stationary devices are based on Raspberry Pi microcontroller and Plantower PMS7003 PM sensor as shown in Fig. 1. (a) and (b). The stationary device supplemented with a DHT22 humidity and temperature sensor. The mobile device has the BME280 sensor for the ambient parameters like humidity, temperature and pressure. To follow the position of the mobile device a NEO-6M GPS module were attached. The mobile device's time was set to the stationary device and the DS3231 internal clock helped to keep it for the whole measurement. The low-cost PM sensors reliabilities were studied before $[7,16]$, according to their data tables they operate with $10-15 \%$ error limit.

(a)

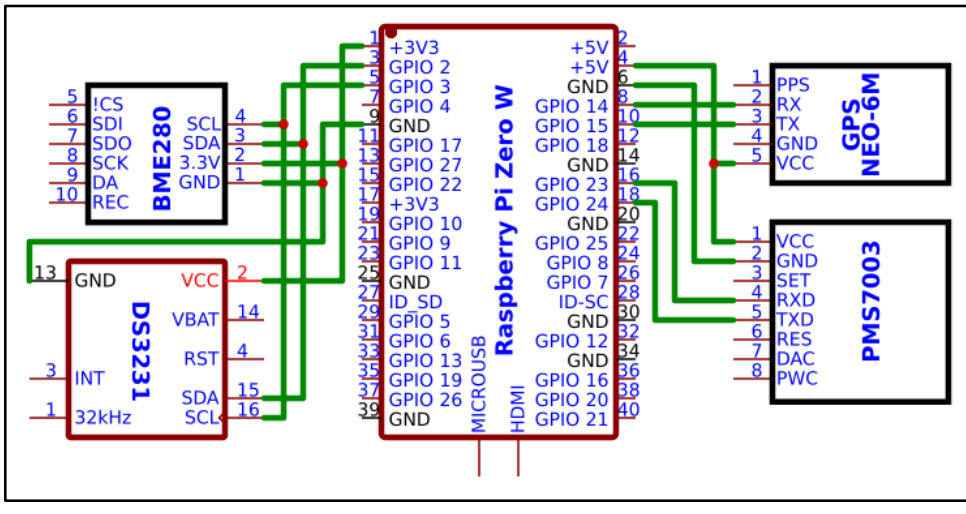

(b)

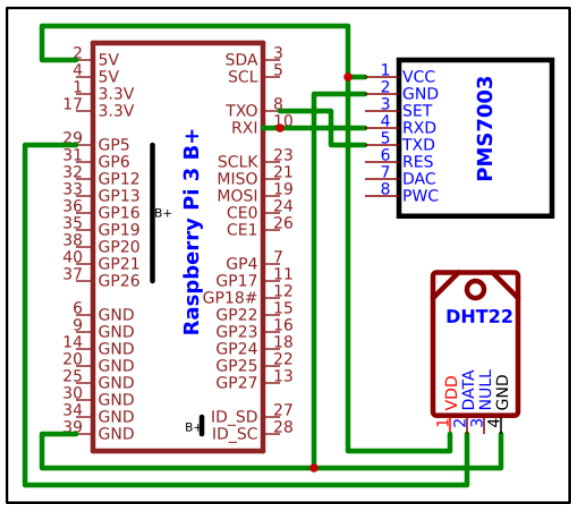

Figure 1. (a) Schematic of mobile device, (b) Schematic of stationary device

The stationary device was placed at the automatic monitoring station of the National Air Quality Measurement Network (OLM) in Martintelep, Miskolc in $4 \mathrm{~m}$ height. The mobile device was used to walk 4 streets along a square route with a total length of $800 \mathrm{~m}$ placed on a backpack in 1,6 m height. The route includes the OLM monitoring station, a busy road, two bypasses, a parking lot, and a sidewalk blocked by traffic (Fig. 2.). Measurements were made on two days (2019.09.09. and 11.) between $7 \mathrm{am}$ and 9am, which according to preliminary experience coincided with the morning rush hours. Each day 5 circle were made along the presented route within 40 minutes. Data were saved with continuous reading at $0.5 \mathrm{~Hz}$ recording time.

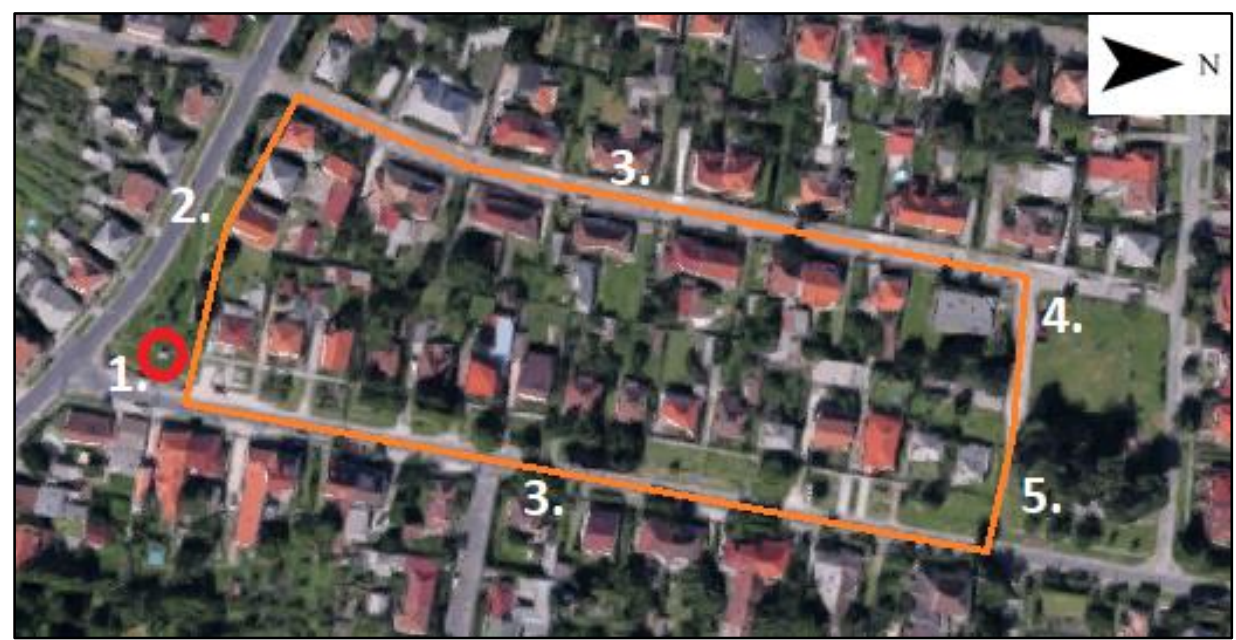

Figure 2. Route of the mobile device (orange square) and placement of stationary device (red circle) 1: OLM monitoring station, 2: busy road, 3: bypasses, 4: parking lot, 5: sidewalk 
We saved GPS coordinates (longitude, latitude, altitude) for the measured data by the help of a mobile device, which allowed us to extend the data spatially. The process was done in ArcGIS 10.1 environment, using the spline interpolation tool (Spline with Barriers). Actually, this tool is a curve minimizing spline that uses lower degreed polynomials (usually third degree polynomials) to build up the function. This secure, that the value of the function, the first and second derivatives of it will be the same (at the measurement point). The advantage of the method is the smoothness, and the disadvantage is that it can give outlier values for the areas further away from the points [17-19].

\section{Results and discussion}

The average concentrations from five circles on 2019.09.09. show on Fig 3. for the three PM concentrations. The PM1, PM2.5 also PM10 concentrations are lower on the north-east (NE) side and higher on south-west (SW) part of the rout. At the NE side is an extensive green area blocked by traffic, which can reduce the PM concentrations.

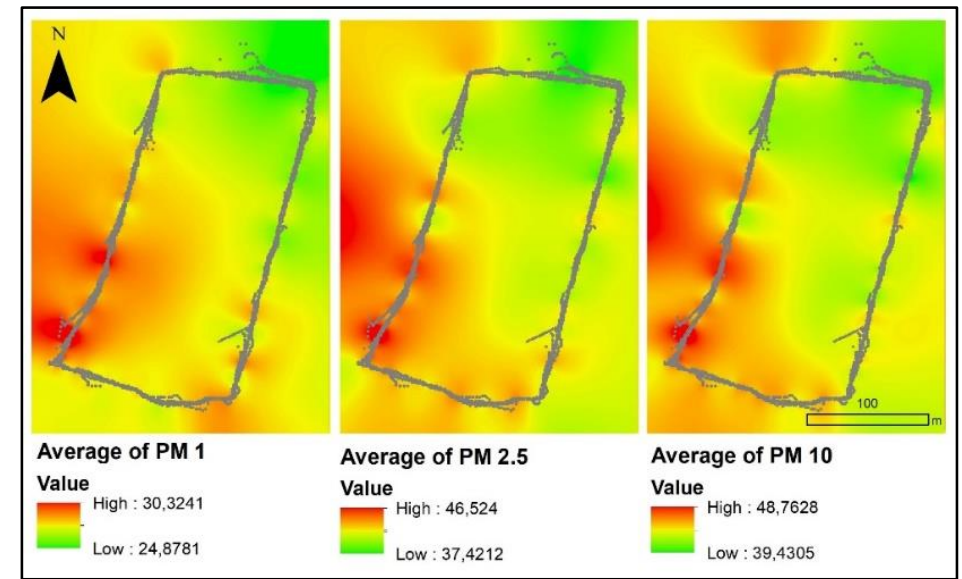

Figure 3. Average concentration maps in $\mu \mathrm{g} / \mathrm{m}^{3}$ from five circles on 2019.09.09.

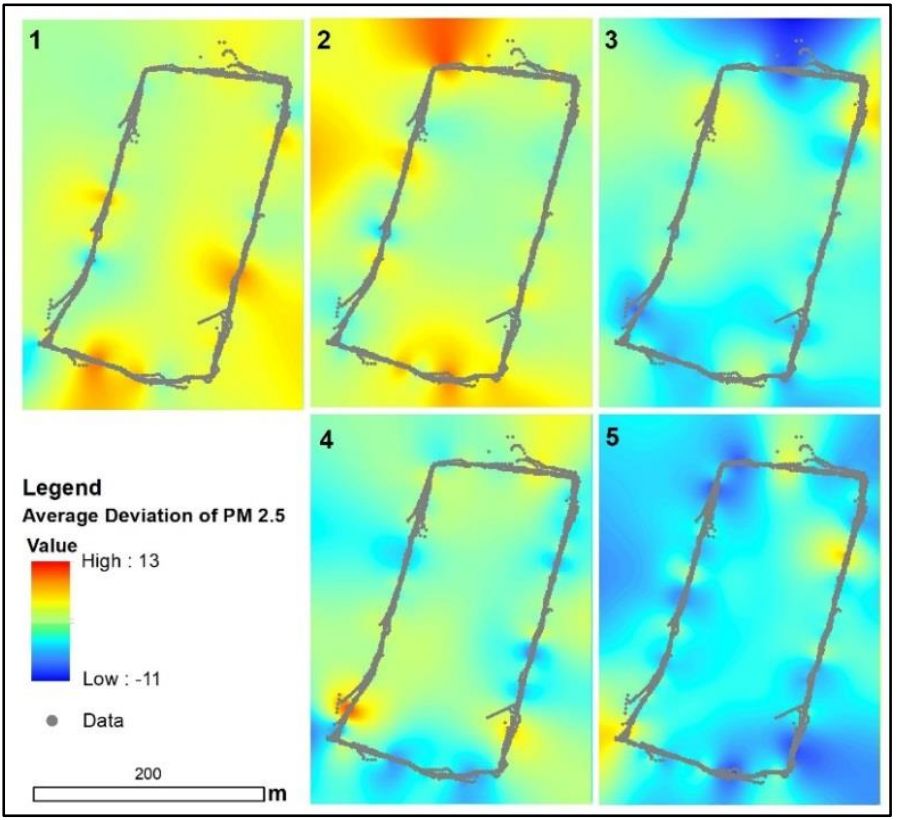

Figure 4. Average deviation maps in $\mu \mathrm{g} / \mathrm{m}^{3}$ for the five circles on 2019.09.09. 
The Fig. 4. shows the average deviations of PM2.5 from circle to circle. The positive deviations show punctual but not recurrent pollution, which means that the sources of these elevated concentrations were vehicles.

The average concentrations from five circles on 2019.09.11. show on Fig 5. for the three PM concentrations. The PM1, PM2.5 also PM10 concentrations are higher on the NE side and lower on SW part of the rout.

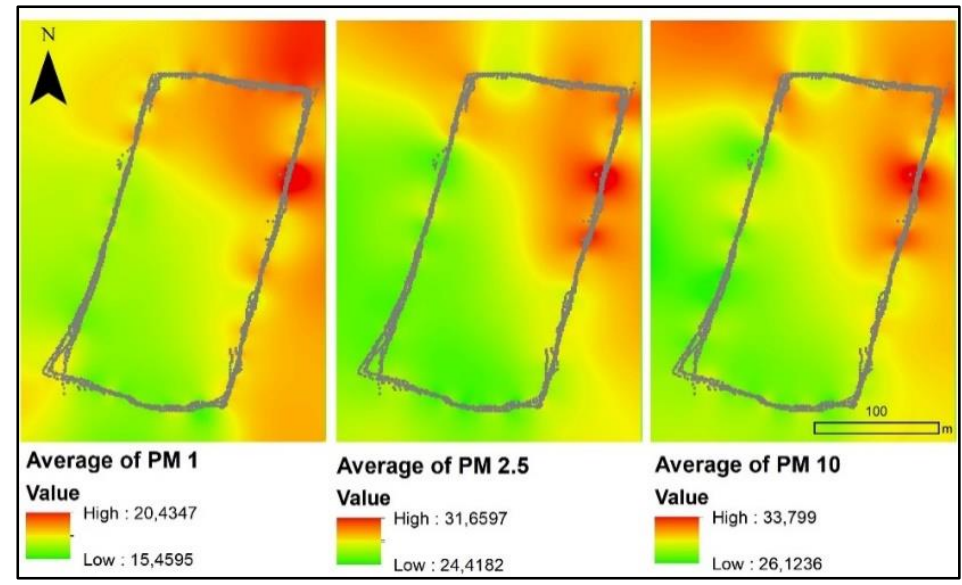

Figure 5. Average concentration maps in $\mu \mathrm{g} / \mathrm{m}^{3}$ from five circles on 2019.09.11.

On this day NNE wind were observed, so the air pollutants were shifted to the south direction. That's how the mapped concentrations are in an opposite way then on 2019.09.09., then pollutants from the busy road dispersed out of the routed way. Altogether the concentration level was lower on the second measurement day, and the high values from the Fig. 5. are even lower than on Fig. 3. It's means that the NE sides concentration was not so different on these two days. The Fig. 6. shows the average deviations of PM2.5 from circle to circle. The positive deviations show punctual but not recurrent pollution, which means that the sources of these elevated concentrations were vehicles. Correlations between PM1 and PM2.5 concentrations along the routes of the two measurement days are under -0.7, between the PM10 concentrations is -0.68 (Table 1.), which confirms the differences between the average concentration maps. As Table .1 shows, the PM2.5 and PM10 concentrations on the same day correlate better than PM1-PM2.5 and even better compared to PM1-PM10 concentrations. 


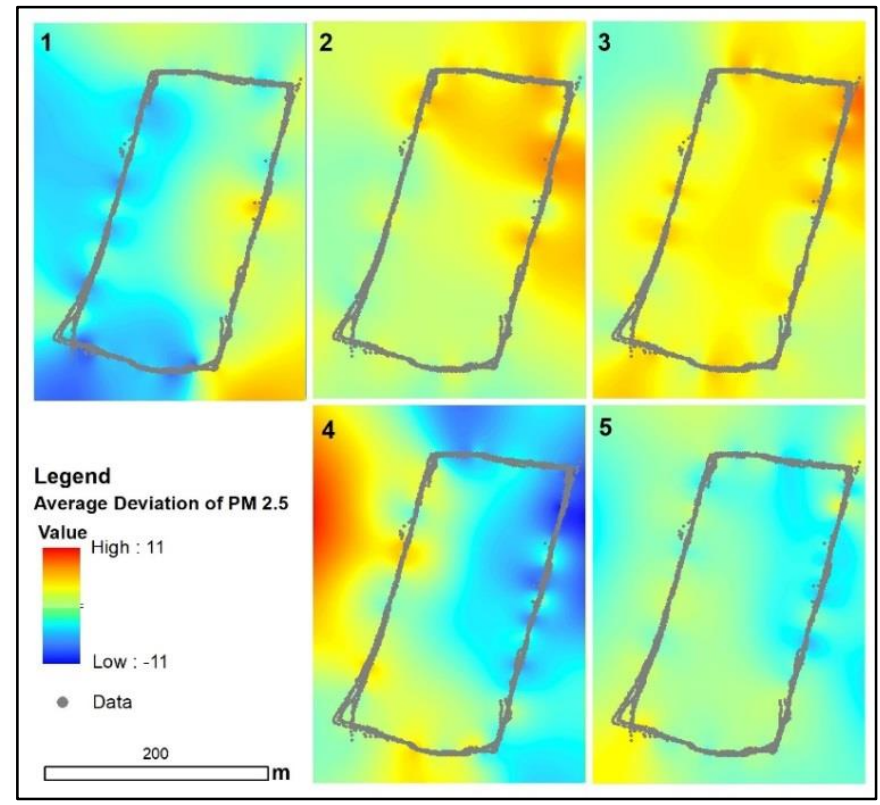

Figure 6. Average deviation maps in $\mu \mathrm{g} / \mathrm{m}^{3}$ for the five circles on 2019.09.11.

From the averaged concentration maps has been collected the average PM concentrations within $10 \mathrm{~m}$ from the place, where the stationary device was placed, namely the OLM station. As Fig. 7. (a) shows the interpolated and averaged concentrations of the mobile device are lower on 2019.09.09. and higher on 2019.09.11. than the measured and averaged concentrations of the stationary device. Comparative measurement was made as both devices were standing on the same place.

\begin{tabular}{|c|c|c|c|c|c|c|c|}
\hline \multicolumn{2}{|c|}{ Day } & \multicolumn{3}{c|}{2019.09 .09} & \multicolumn{3}{c|}{2019.09 .11} \\
\hline \multicolumn{2}{|c|}{ PM concentration } & PM1 & PM2.5 & PM10 & PM1 & PM2.5 & PM10 \\
\hline \multirow{3}{*}{2019.09 .09} & PM1 & 1.00 & 0.84 & 0.80 & -0.79 & -0.78 & -0.73 \\
\cline { 2 - 8 } & PM2.5 & 0.84 & 1.00 & 0.96 & -0.74 & -0.72 & -0.70 \\
\cline { 2 - 8 } & PM10 & 0.80 & 0.96 & 1.00 & -0.71 & -0.68 & -0.68 \\
\hline \multirow{3}{*}{2019.09 .11} & PM1 & -0.79 & -0.74 & -0.71 & 1.00 & 0.88 & 0.81 \\
\cline { 2 - 8 } & PM2.5 & -0.78 & -0.72 & -0.68 & 0.88 & 1.00 & 0.96 \\
\cline { 2 - 8 } & PM10 & -0.73 & -0.70 & -0.68 & 0.81 & 0.96 & 1.00 \\
\hline
\end{tabular}

Table 1. Correlation of averaged PM concentrations between two days

At this steady measurement the average percentage deviation was under $12 \%$. The deviation at the OLM station on 2019.09.09. was under 15\% but on 2019.09.11. was higher as Fig. 7. (b) shows.

(a)
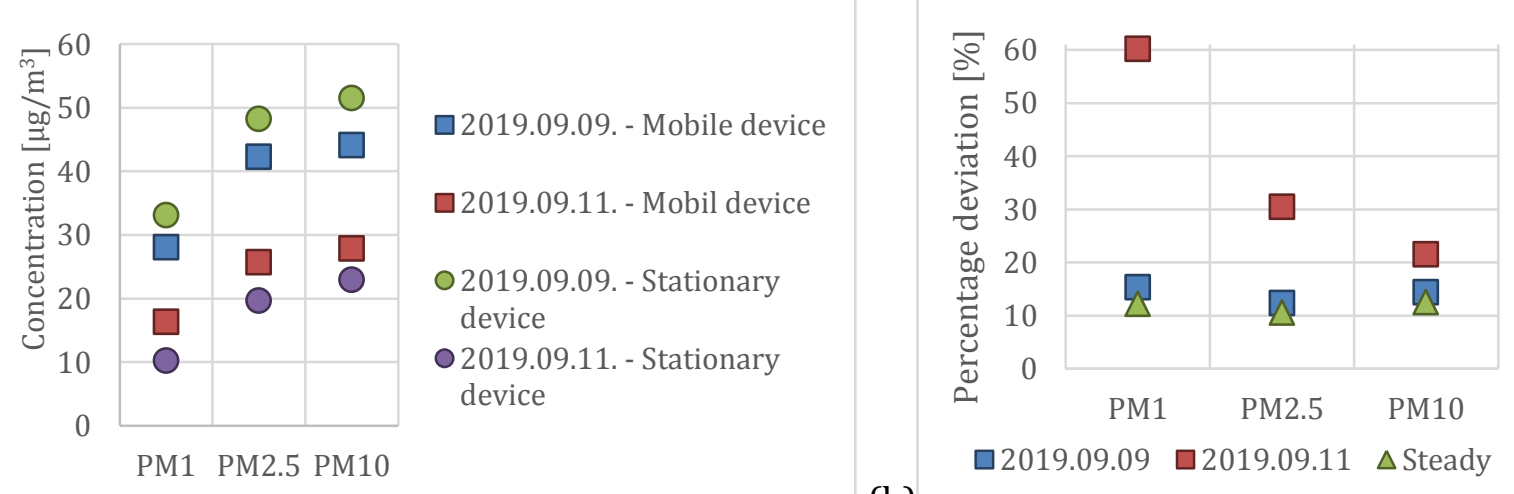

(b)

Figure 7. (a) Averaged PM concentrations of mobile and stationary devices at the OLM station

(b) Percentage deviation of PM concentration of mobile and stationary devices 


\section{Conclusion}

Stationary and mobile PM measurements were made with sensor-based devices, which represents the possibilities of a combined measurement technique. The mobile device is capable to explore an area and identify the higher concentration parts of it. If these are not recurrent and have wind dependence, we can define them as mobile sources (vehicles), if these are recurrent in case of the same wind directions, then we define them as stationary sources. Based on the result of the mobile measurements, the most stable site can be selected to measure with the stationary device. Further research will be supplemented with wind and PM data from OLM station, and measurements in different part of the day, heating and non-heating season also.

\section{Acknowledgement}

The described article/presentation/study was carried out as part of the EFOP-3.6.1-16-2016-00011 "Younger and Renewing University - Innovative Knowledge City - institutional development of the University of Miskolc aiming at intelligent specialisation" project implemented in the framework of the Szechenyi 2020 program. The realization of this project is supported by the European Union, co-financed by the European Social Fund.

\section{References}

[1] A. Valavanidis, K. Fiotakis, and T. Vlachogianni, Airborne particulate matter and human health: toxicological assessment and importance of size and composition of particles for oxidative damage and carcinogenic mechanisms. Journal of Environmental Science and Health, Part C, 2008. 26(4): p. 339-362.

[2] L. Jimoda, Effects of particulate matter on human health, the ecosystem, climate and materials: a review. Facta universitatis-series: Working and Living Enviromental Protection, 2012. 9(1): p. 27-44.

[3] Air quality criteria for particulate matter. Vol. 3. 1996: US Environmental Protection Agency, Office of Research and Development, National Center for Environmental Assessment.

[4] WHO, Air Quality Guidelines: Global Update 2005. Particulate Matter, Ozone, Nitrogen Dioxide and Sulfur Dioxide. 2006: World Health Organization.

[5] Directive 2008/50/EC of the European Parliament and of the Council of 21 May 2008 on ambient air quality and cleaner air for Europe. Official Journal of the European Union, 2008.

[6] K. N Genikomsakis, et al., Development and On-Field Testing of Low-Cost Portable System for Monitoring PM2. 5 Concentrations. Sensors, 2018. 18(4): p. 1056.

[7] T. Sayahi, A. Butterfield, and K. Kelly, Long-term field evaluation of the Plantower PMS low-cost particulate matter sensors. Environmental Pollution, 2019. 245: p. 932-940.

[8] H. Magen Molho, et al., Application of a sensor network of low cost optical particle counters for assessing the impact of quarry emissions on its vicinity. 2019.

[9] F. Gozzi, G. Della Ventura, and A. Marcelli, Mobile monitoring of particulate matter: State of art and perspectives. Atmospheric Pollution Research, 2016. 7(2): p. 228-234. 
[10] T. Cao and J.E. Thompson, Portable, ambient PM2. 5 sensor for human and/or animal exposure studies. Analytical Letters, 2017. 50(4): p. 712-723.

[11] S. Firląg, M. Rogulski, and A. Badyda, The Influence of Marine Traffic on Particulate Matter (PM) Levels in the Region of Danish Straits, North and Baltic Seas. Sustainability, 2018. 10(11): p. 4231.

[12] R. Sullivan and S. Pryor, Quantifying spatiotemporal variability of fine particles in an urban environment using combined fixed and mobile measurements. Atmospheric Environment, 2014. 89: p. 664-671.

[13] B.G. Loh and G.H. Choi, Calibration of Portable Particulate Matter-Monitoring Device using Web Query and Machine Learning. Safety and Health at Work, 2019.

[14] N. Castell, et al., Can commercial low-cost sensor platforms contribute to air quality monitoring and exposure estimates? Environment international, 2017. 99: p. 293-302.

[15] A. Lewis and P. Edwards, Validate personal air-pollution sensors: Alastair Lewis and Peter Edwards call on researchers to test the accuracy of low-cost monitoring devices before regulators are flooded with questionable air-quality data. Nature, 2016. 535(7610): p. 29-32.

[16] K. Kelly, et al., Ambient and laboratory evaluation of a low-cost particulate matter sensor. Environmental pollution, 2017. 221: p. 491-500.

[17] W. Smith and P. Wessel, Gridding with continuous curvature splines in tension. Geophysics, 1990. 55(3): p. 293-305.

[18] S. Zoraster, A surface modeling algorithm designed for speed and ease of use with all petroleum industry data. Computers \& geosciences, 2003. 29(9): p. 175-182.

[19] T. Telbisz, B. Székely, and G. Timár, Digitális Terepmodellek-Adat, látvány, elemzés. ELTE TTK FFI Természetföldrajzi Tanszék, Budapest, 2013: p. 23-69. 